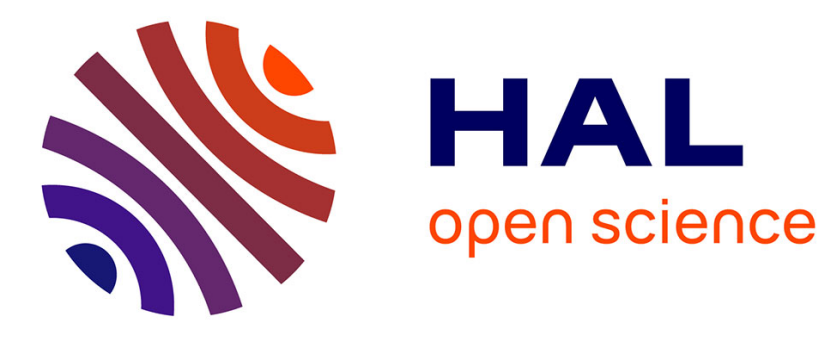

\title{
Laser Barcode-based Surgical Instrument Tracking System
}

\author{
Ali Findik, Ozgun Pinarer, Sultan Turhan
}

\section{To cite this version:}

Ali Findik, Ozgun Pinarer, Sultan Turhan. Laser Barcode-based Surgical Instrument Tracking System. 2017 25th Signal Processing and Communications Applications Conference (SIU), May 2017, Antalya, Turkey. pp.1-4, 10.1109/SIU.2017.7960441 . hal-02380164

\section{HAL Id: hal-02380164 https://hal.science/hal-02380164}

Submitted on 10 Feb 2020

HAL is a multi-disciplinary open access archive for the deposit and dissemination of scientific research documents, whether they are published or not. The documents may come from teaching and research institutions in France or abroad, or from public or private research centers.
L'archive ouverte pluridisciplinaire HAL, est destinée au dépôt et à la diffusion de documents scientifiques de niveau recherche, publiés ou non, émanant des établissements d'enseignement et de recherche français ou étrangers, des laboratoires publics ou privés. 
archives-ouvertes

\section{Laser barcode-based surgical instrument tracking system} Ali Findik, Ozgun Pinarer, Sultan Turhan

\section{To cite this version:}

Ali Findik, Ozgun Pinarer, Sultan Turhan. Laser barcode-based surgical instrument tracking system. 2017 25th Signal Processing and Communications Applications Conference (SIU), May 2017, Antalya, Turkey. pp.1-4, 10.1109/SIU.2017.7960441 . hal-02380164

\section{HAL Id: hal-02380164 \\ https://hal.archives-ouvertes.fr/hal-02380164}

Submitted on 10 Feb 2020

HAL is a multi-disciplinary open access archive for the deposit and dissemination of scientific research documents, whether they are published or not. The documents may come from teaching and research institutions in France or abroad, or from public or private research centers.
L'archive ouverte pluridisciplinaire HAL, est destinée au dépôt et à la diffusion de documents scientifiques de niveau recherche, publiés ou non, émanant des établissements d'enseignement et de recherche français ou étrangers, des laboratoires publics ou privés. 


\title{
Lazer Barkod Destekli Cerrahi Alet Takip Sistemi Laser Barcode-based Surgical Instrument Tracking System
}

\author{
Ali Findik*, Ozgun Pinarer ${ }^{\dagger}$, Sultan Turhan ${ }^{\dagger}$ \\ *Alfion Yazılım Çözümleri \\ Yıldız Posta Cad. Akın Sitesi 6/20, 34349, Istanbul, Türkiye \\ Email: ali.findik@alfion.com.tr \\ ${ }^{\dagger}$ Galatasaray Üniversitesi, Bilgisayar Mühendisliği Bölümü \\ Çırağan Cad. No:36, 34349, İstanbul, Türkiye \\ Email: \{opinarer, sturhan\}@gsu.edu.tr
}

\begin{abstract}
Özetçe -Yeni teknolojiler hayatın her alanında karşımıza çıktığı gibi insan sağlı̆̆ı alanında da kendisine yer bulmaktadır. Bu bildiride sağlık kurumlarının vazgeçilmez bir parçası olan cerrahi aletlerin takibi üzerine bir çalışma sunulmaktadır. Çalışma dahilinde üzerlerine lazer yazıcılar ile kare barkodlar yerleştirilen cerrahi aletlerin takibini sağlayan uygulama tabanlı bir sistem geliştirilmiştir. Gerek literatür gerekse endüstriyel anlamda cerrahi alet takip sistemleri prototip aşamasında olup, yerli bir yazılıma, Türkçe ve kullanıcı dostu bir arayüze sektörün ihtiyaç duyduğu fizibilite çalışmaları sonucu tespit edilmiştir. Bu ihtiyaca cevap vermek adına bu bildiride sağlık kurumlarındaki cerrahi aletlerin takibini gerçekleştiren Cerrahi Alet Takip Sistemi (CATS) sunulmaktadır. Özellikle merkezi sterilizasyon ünitesi ve sağlık kurumunun çeşitli birimlerine yerleştirilen optik barkod okuyucular ve kullanıcı dostu iş istasyonları ile cerrahi aletlerin takibi sağlanmaktadır. Bu çalışma ile sterilizyon döngüsünün her etabı kontrol edilebilmektedir. Sistem, ayrıca cerrahi aletlerin kaybolmasını (ve çalınmasını) engellemeyi, eksik konteynerleri daha hızlı ve etkili bir şekilde belirlemeyi hedeflemiştir ${ }^{1}$.
\end{abstract}

Anahtar Kelimeler-sağlık bilişimi, veri yönetimi, sterilizasyon islemi

Abstract-New technologies involve in health domain as in every field of our entire life. This paper presents a study on the surgical instruments which are an indispensable part of health institutions. In the study, an application-based software approach is introduced to track the surgical instruments on which square barcodes were placed via laser printers. Either in the literature or in the industrial sense, the surgical instrument tracking systems are at the prototype stage. The result of the feasibility studies clearly indicates the major requirements of this industrial domain: Turkish and user-friendly interface, efficiency and dynamic surgical instrument tracking system. In order to answer these needs, in this paper, Surgical Instrument Tracking System (CATS), which performs the monitoring/tracking of surgical instruments in health institutions, is presented. In particular, the track of these tools is provided via optic barcode readers and user-friendly workstations that are placed in various units of the healthcare institution (especially in centralized sterilization unit). With this study, every phase of sterilization cycle can be controlled. The system also aims to prevent the loss (and theft)

\footnotetext{
${ }^{\mathrm{I}} \mathrm{Bu}$ çalısma Galatasaray Üniversitesi Bilimsel Arastırma Projeleri (BAP) tarafından 15.401.003 numaralı proje kapsamında desteklenmiştir.
}

of surgical instruments and to determine missing/incomplete surgical containers more quickly and effectively.

Keywords-health informatics, central sterilization unit, health data management.

\section{GİRIŞ}

Günümüzde hızla gelişen teknoloji sayesinde bilişim hizmetleri günlük hayatımızın her alanında vazgeçilmez bir unsur olarak yer almaktadır. Bilişim teknolojilerinin bu hızlı gelişimi dünya çapında tüm sektörleri etkilediği gibi sağlık sektörünü de dikkat çekici bir şekilde etkilemiştir. Toplumların gelişmişlik göstergeleri içinde ayrı bir yere sahip olan eğitim ve sağlık sektörlerinden sağlık sektörünün her alanında, gelişen bilişim teknolojileri ile oluşturulan yeni iş süreçlerine tanık olmak mümkündür. Üstelik bahsi geçen bu yeni hizmet süreçleri sadece teşhis, tedavi ya da cerrahi müdahale gibi tıbbi alanlarda değil, bu alanlara 7 gün 24 saat aralıksız destek veren hastane yönetimi ya da tıbbi malzeme tedarik zinciri gibi lojistik destek birimlerinin işleyişlerinde de modellenmektedirler.

Ülkemizdeki sağlık kurumlarının mevcut durumları incelendiğinde, her kurumun kendine ait, kendine özel geliştirilen ya da sektördeki ortak ihtiyaçlar göz önünde bulundurularak geliştirilmiş "Hastane Bilgi Sistemi" adı verilen bir yazılım ve bunu destekleyen altyapı bileşenlerini kullandığı gözlemlenmektedir. Her ne kadar her kurum, farklı altyapı teknolojileri kullanılarak geliştirilmiş farklı bir sistem kullanıyor olsa da, hepsinin kullanım amaç ve alanları ortaktır: güvenlik ve bilgi erişimi, hasta kaydı, poliklinik, klinik, tıbbi kayıt, radyoloji, eczane, laboratuvar, ameliyathane, doğum odas1, acil servis, döner sermaye ve muhasebe, bordro, personel yönetimi, stok kontrol ihale dosyaları, satın alma, demirbaşların takibi, v.b. Kısacası sektördeki mevcut sistemler daha çok hasta ve personel odaklı olup, kurumun rutin faaliyetlerini yerine getirmek amacıyla kullanılmaktadır.

Sağlık kurumlarının kullandıkları teçhizatlar arasında, hastalık teşhisinde kullanılan özel medikal cihazlar ile ameliyathane ve küçük tıbbi müdahalelerde kullanılan cerrahi aletler (ve de ilk yardım ve pansuman işlemler için kullanılan 
sarf malzemeler) farklı bir öneme sahiptirler. Sağlık hizmetinin kesintisiz olarak verilmesinde, sözü geçen medikal cihazların düzenli bakımının yapılması takip edilmesi ne kadar önemli ise büyük ve küçük tıbbi müdahalelerde kullanılan cerrahi aletlerin de sterilizasyonu ve takibi aynı önemi haizdir. Üstelik bu aletler yüksek edinim maliyetlerinin yanı sıra sterilizasyon işlemiyle birlikte ek bir kullanım maliyeti ile sağlık kurumunun bütçesinde önemli bir kalem teşkil etmektedir.

Kullanılan her cerrahi aletin, kullanım sonrasında sterilizasyon işlemine tabi tutulup, bir sonraki kullanım için hazırlanması gerekmektedir. Öte yandan kullanılmasa da, aletler önceden tanımlanmış bir müddet boyunca kullanılmadığ için, yeni bir sterilizasyona tabi tutulmaları gerekir. Ayrıca hastane tarafindan satın alınan her cerrahi aletin de steril edilmesi gerekmektedir [1].

$\mathrm{Bu}$ bildiride sağlık kurumlarında yaşanan problemler ele alınmış olup bu sorunları gidermek amacıyla uygulama tabanlı bir yazılım çözümü önerilmiştir: Cerrahi Alet Takip Sistemi (CATS). CATS ile lazer yazıcılar yardımıla üzerilerine barkod yazılan cerrahi aletlerin takibi mümkün kılınmaktadır. Cerrahi aletlerin kurumun iç işleyişinde geçirdiği evreler mercek altına alınıp, cerrahi alet takip sistemi geliştirilmiştir. Çalışma dahilinde sağlık kurumunun başta merkezi sterilizasyon ünitesi (MSÜ) başta olmak üzere fizibilite çalışması ile belirlenen yerlerine optik barkod okuyucular ve sistemi kullanmaya olanak sağlayan dokunmatik terminaller yerleştirilmiştir. Cerrahi aletlerin ilk alımlarından itibaren, cerrahi aletlerden oluşan konteynerlerin takibi ve cerrahi setlerin sterilizasyon işlemlerinin her adımı geliştirilen sistem ile takip edilebilmektedir. $\mathrm{Bu}$ çalışma ile sağlık kurumlarındaki cerrahi aletlerin kaybolmaları engellenmekte, insan sağlığ 1 açısından kritik öneme sahip olan ameliyat sırasında hasta vücudu içerisinde unutma gibi vakaların önüne geçilmektedir.

Bildirinin geri kalanı şu şekilde bölümlendirilmiştir: Bölüm II'de literatürdeki benzer çalışmalar anlatılmıştır. Önerilen yaklaşım Bölüm III'te sunulmuştur. Önerilen sistemin bileşenleri Bölüm IV'de belirtilmiş olup Bölüm V'te sistem çıktıları ve artıları sunulmuştur. Elde edilen çıkarımlar ise Bölüm VI'te verilip genel değerlendirmelerde bulunulmuştur.

\section{BENZER ÇALIŞMALAR}

Ameliyat sirasında steril dokular ve steril vücut boşluklarında kullanılan tüm cerrahi malzemeler Spaulding sinıflamasında (cerrahi aletlerin mantıksal olarak sınıflandırması taşıdıkları risk gruplarına göre oluşturulmuştur: kritik, yarı kritik, kritik olmayan) da belirtildiği gibi kritik malzemelerdir ve tekrar kullanmadan önce steril edilmeleri gerekmektedir. Isıya dayanıklı olan cerrahi aletler yüksek 1sıda(buhar otoklav) steril olurken yüksek isıda bozulabilen yada özelliği kaybolan hassas malzemelerin de gün içinde tekrar kullanıma hazırlanması önem teşkil etmektedir [2].

Diğer yönden, Şişli Etfal EAH 2012 verilerine göre belirtilen sene içerisinde yaklaşık olarak 35.106 ameliyat, girişimsel radyolojide 2266 girişimsel işlem ve 14.789 GI Endoskopi gerçekleştirilmiştir. Sağlık kurumlarında, görüldüğü üzere aynı cerrahi aletlere günden birden fazla kere ihtiyaç duyulmaktadır. Bu sebepten cerrahi aletlerin başta sterilizasyonu olmak üzere takip edilmesi son derece kritik öneme sahiptir.

$\mathrm{Bu}$ projede sunduğumuz cerrahi alet ve sterilizasyon takibi Türkiye sağlık sektöründe çok yeni bir yaklaşımdır. Günümüzde sağlık kurumlarının en büyük sorunlarından birinin cerrahi aletler olduğunu belirtmiştir. Bu cerrahi aletlerin sağlık kurumu içerisinde kaybedilmesi, eksik cerrahi set durumlarından dolayı oluşan maliyetleri sebebiyle cerrahi alet takip sisteminin önemli bir ihtiyaç olduğu yapılan çalışmalar sonucunda belirlenmiştir. Gerek sterilizasyon takibinin sağlanması açısından, gerekse malzeme kaybını azaltmasını hedeflediği için maliyet açısından sağlık kurumuna önemli faydalar sağlayacağı amaçlanmaktadır.

Türkiye'de sağlık sektöründe sağlık kurumlarına cerrahi aletleri takip etmek amacıyla sunulan yazılım destekli uygulama çözümleri yeteri kadar gelişmemiştir. Özellikle projede sunulan barkodlama ile cerrahi aletlerin gerek takibi, gerek depoda sterilizasyonu tamamlanmış setlerin optimal kullanımı gerekse tüm bunların raporlamasını bir arada sunan bir çözüm piyasada bulunmamaktadır. Yabancı menşeli $3 \mathrm{M}$ firmasının yurtdışında sektördeki bu eksikliğe çözüm bulmak amacıyla bir takım uygulamaları mevcut olsa da Türkiye pazarına yeni giriş yapmakta olup Türk sağlık sektörüne ne kadar uyum sağlayacağı soru işareti olarak kalmaktadır.

Sterilizasyon takibinin ise bir sağlık kurumu için ne kadar elzem olduğu daha önce yapılan çalışmalarda ortaya konmuştur. [3] merkezi sterilizasyon ünitelerinin sağlık kurumunun en önemli bölümü olduğunu ve bu bölümde yaşanabilecek bir sorunun tüm sağlik kurumunu etkilediğini belirtmektedir. $\mathrm{Bu}$ sebepten cerrahi aletlerin sterilizasyonu işleminin ve bu işlemin gerçekleştiği ünitenin kontrol edilmesi üzerine sterilizasyon işleminin tasarımı ve yönetimi üzerine çalışma sunmaktadır. $\mathrm{Bu}$ çalışma, sağlık kurumlarında gerçekleştirilen sterilizasyon işleminin hangi teknoloji veya hangi yöntem ile takip edilebileceği konusunda bilgi vermemekte olup, sektördeki ihtiyacı yansıtan bir çalışma olarak kalmıştır.

[4] sağlık kurumlarındaki sterilizasyon işleminin döngüsünü, döngünün her bir parçasının nasıl gerçekleşmesi gerektiğini detaylı bir şekilde açıklamıştır. Merkezi sterilizasyon ünitesinin mimari yapısı ve bu mimari yapıda görev alan sağlık kurumu personellerinin iş tanımlarını açıkça belirtmiştir. Benzer bir çalışma, 2016 yılında Türkiye Cumhuriyeti Milli Eğitim Bakanlığı tarafindan "Sağlık Hizmetleri”" konu başlığı altında araştırılmış ve sterilizasyon işleminin yapısı ve işleyişi yönerge şeklinde sağlık kurumlarına ve personellerine sunulmuştur. Fakat yapılan bu çalışmaların hiçbiri, sterilizasyon işleminin düzgün bir şekilde yapılıp yapılmadığını kontrol etmemektedir. Ayrıca sağlık kurumunda kullanılan cerrahi aletlerin takibi hakkında herhangi bir öneri sunmamaktadir.

Sonuç olarak kare barkodlama tekniği ile cerrahi alet kaybının en aza indirildiği, kare barkodlama sistemi ile kaybolan cerrahi el aletlerinin hangi safhada kaybolduğu kolaylıkla saptanabilmektedir [5]-[7]. Bununla beraber cerrahi aletlerin kaç kez steril edildiğinin saptanabilmesi, kalan steril sürelerinin takiplerinin yapılabilmesi, arıza süreçlerinin takibi, kullanıldığ1 ameliyatlar ve kullanan kişilerin sistemden takip edilebilmesi CATSin artıları arasında yer almaktadır. 


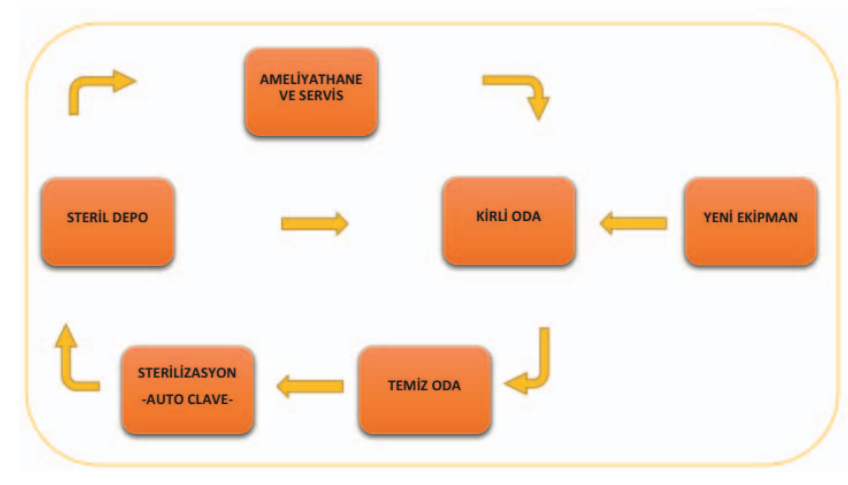

Şekil 1: CATS Akış Şeması.

\section{III. ÖNERILEN YAKLAŞIM}

Bugün bir çok sağlık kurumunda, cerrahi aletlerin kaybolması, setlerin içerisinde bazı aletlerin eksik olması ve daha önemlisi yapılan cerrahi müdahale esnasında hastanın vücudunda aletin unutulması gibi vakalarla maalesef halen karşılaşılmaktadır. $\mathrm{Bu}$ sebeple hem bu aletleri, aletlerin oluşturduğu setleri ve ilgili envanterleri takip edebilmek, hem de sterilizasyon süreçlerinin düzgün işlediğinden emin olabilmek amaciyla "cerrahi alet sterilizasyon takip sistemine" ihtiyaç duyulmaktadır.

Bu çalışmanın amacı, sektörde hali hazırda kullanılmakta olan mevcut sağlık kurumu bilgi sistemleri yazılımlarını bünyesinde bulunmayan, ancak bir sağlık kurumu için oldukça önemli olan cerrahi alet sterilizasyon takip sistemi için ihtiyaç duyulan süreçleri modellemek ve ortaya konulan yeni iş süreçleri destekleyecek bir altyapı mimarisi ve yazılımını geliştirmektir.

Ayrıca cerrahi alet ve setlerin kullanan tıbbi personel, kullanım zamanı ve kullanım yeri boyutları ile takip edilmesini kolaylaştıracak olan bu sistem sayesinde sağlık kurumlarının sıkça karşılaştığı cerrahi aletlerin kaybolma probleminin de önüne geçilmesi hedeflenmektedir.

Önerilen yaklaşım, barkod-optik okuyucu sistemi ile gerçeklenip, mümkün olduğu kadar klavye-fare uç birimlerinden bağımsız, son derece kullanıcı dostu bir mimariye sahip olacaktır. Sağlık kurumu binasında, hizmet alanlarına fiziksel olarak yerleştirilecek barkod okuyucular, barkod yazıcı cihazlar sayesinde sistem kullanıcı etkileşimi minimize ederek hizmet almasını sağlayacaktır.

CATS, sağlık kurumlarına yukarıda belirtilen hizmetleri sunmasının yanı sıra, son yıllarda Türkiye'de oluşmakta olan ve bünyelerinde birden fazla sağlık kurumunu bulunduran zincir sağlık kurumu gruplarının karar alıcılarına hizmet verebilecektir. Grubu oluşturan sağlık kurumlarının birbirleri arasındaki etkileşimi, bu kurumların yönetim birimlerinin sağlık kurumlara olan bağlantısı geliştirilecek yazılımda desteklenmektedir. Ayrıca sektörde devlet kurumları tarafında, Türkiye genelinde 88 özel bölgede kurulmuş olan Kamu Hastaneleri Birliği yönetimlerine de,bünyelerinde bulunan sağlık kurumlarına ait cerrahi alet teçhizatlarına ve sterilizasyon bilgilerinin takibini, stok yönetimi ve raporlama gibi hizmetleri sağlayacaktır.
Sunulan yaklaşıma ait sterilizasyon döngüsünüde kapsayan CATS akış şeması Şekil-1'de gösterilmiştir. Verilen şekilde de görüldüğü üzere, tipik bir sterilizasyon işlemi kirli oda-temiz oda-depo olmak üzere üç bölümden oluşmaktadır. Yeni alınan, kullanılan ya da kullanılmadığ 1 halde steril olma özelliği yitirmiş olan cerrahi aletler kirli odada toplanır. Bu odada önce standart temizleme işlemi gerçekleştirilir ve temiz odaya gönderilir. Ardından temiz odada sterilizasyon işlemi yapılır ve özel setler halinde gruplanarak ya doğrudan kullanıma ya da ihtiyaç halinde kullanılması için depoya gönderilir. Bu döngü içerisindeki her bir adım yüksek öneme sahip olup insan sağlığı açısından kritik bir işlemdir. Bu sebeple sterilizasyon işleminin her adımı muhakkak takip edilmeli ve raporlanmalıdır.

\section{SİSTEM BİLEŞENLERI}

Sistem bileşenleri ve temel işlevleri aşağıda sıralanmıştır. Sunulan CATS temel olarak 7 adet bileşenden oluşmaktadır:

\section{A. Kullanıcı Giriş̧ Modülï}

- Kullanıcı adı ve şifre ile kullanıcı girişi işlemi

- Kullanıcıları görüntüleme, kullanıcı ekleme, düzenleme ve silme fonksiyonları

- Kullanıcı yetkilendirme fonksiyonları

- Yaka kartlarına yerleştirilecek etiketleri yazan etiket yazıcinın entegrasyonu

- Yaka kartı etiketi yazdırma fonksiyonu

- Yaka kartlarına yerleştirilen barkodları okuyacak barkod okuyucunun entegrasyonu

- Yaka kartı okutma ile kullanıcı girişi işlemi

\section{B. Cerrahi Alet, Set ve Sarf Malzeme Tanımlama Modülü}

- Setlerin ve cerrahi aletlerin yaratılmasi, görüntülenmesi, düzenlenmesi ve silinmesi fonksiyonları

- Sarf malzemelerin yaratılması, görüntülenmesi, düzenlenmesi ve silinmesi fonksiyonları

- Cerrahi alet okumak için uygun barkod okuyucunun entegrasyonu

\section{Set Yapma Modülï}

- Set açma fonksiyonu

- Cerrahi alet okuma ve setle ilgili işlem yapma fonksiyonları

- Arızalı alet, eksik alet kayıt fonksiyonu

- Set kapama fonksiyonu

\section{Yıkama Cihazı Modülü}

- İlk yıkama yükleme, çalıştırma, tamamlama ve iptal etme fonksiyonları

- Autoclave yükleme, çalıştırma, tamamlama ve iptal etme fonksiyonları 


\section{E. Toplu Üretim Paketleme Modülü}

- Toplu üretim oluşturma fonksiyonu

- Toplu üretim için etiket üretme fonksiyonu

- Toplu üretimleri görüntüleme, düzenleme ve silme fonksiyonları

\section{F. Steril Depo Modülü}

- Steril depo mobil terminalinde setlerin depoya girişini, çıkışını sağlayan fonksiyonlar

\section{G. Ameliyathane Modülü}

- Ameliyathane mobil terminalinde set giriş/çıkış fonksiyonları

\section{SISTEM ÇIKTILARI}

$\mathrm{Bu}$ bildiride sunulan yaklaşım ile sağlık kurumunda bulunan cerrahi aletlerin, sarf malzemelerin, başka sağlık kurumlarına ödünç verilen cerrahi setlerin takibi sağlanmıştır. Cerrahi aletlerin, konteynerlerde, sepetlerde, yeşil bezlerde paketleme yöntemi kullanılarak işaretlenmesi ve takip edilmesi mümkün olmuştur. Bu yaklaşım ile tüm cerrahi setler sisteme tanıtıldığından setlerin yönetilmesi daha kolay hale gelmiştir.

Ayrıca çalışma dahilinde raporlama işlemini gerçekleştiren bir iş paketi de gerçekleştirilmiştir. Bu iş paketi sayesinde cerrahi aletlerin kullanımına dair (arızalı aletler, eksik aletler, son kullanma tarihi yaklaşan veya geçmiş setler v.b.) raporlar elde edilebilmektedir.

Yeni teknolojiler ile gerçekleştirilen CATS kullanıcısına Türkçe ve son derece kullanıcı dostu bir arayüz ve çalışır bir altyapı sunmaktadır. Sistem verilerini hızı ve etkili bir şekilde işleyebilecek şekilde tasarlanan mimarisi ile yüksek performans, esneklik ve dinamiklik getirmektedir. Sağlık kurumlarına kurulan bu sistemin ayrıca şifreli olarak yedeklenmesi de yine proje dahilinde gerçekleştirilmiştir. $\mathrm{Bu}$ sayede sağlık kurumuna ait özel bilgilerin güvenli bir şekilde saklanması sağlanmıştır.

\section{SONUÇ}

Günümüz sağık kurumlarında en stk rastlanan sorunlar: cerrahi aletlerin kaybolması ve zarar görünmesi, arızaya gönderilen aletlerin tespit ve takip edilememesi, steril kalma süresi sona eren cerrahi aletlerin takip edilmesinin zor oluşu, kaybolan cerrahi aletlerin sağlik kurumunu ekonomik kayba uğratması ve takip sistemi için kullanılabilecek benzer sistemlerin kullanıcı dostu ve Türkçe bir arayüze sahip olmamaları şeklinde sıralanabilir.

$\mathrm{Bu}$ çalışmada yukarıda belirtilen gereksinimlere cevap vermesi, cerrahi aletlerin takibini kolaylaştırmak ve verimli şekilde kullanılmalarını sağlamak amacıyla geliştirilen Cerrahi Alet Takip Sistemi (CATS) sunulmuştur.

Çalışma ile tüm cerrahi aletlerin ve setlerin hangi tarihte, nerede olduğunu ve kim tarafindan işleme alındığını kontrol ve takip etmek mümkündür. Ayrıca, önerilen yaklaşım ile sterilizasyon sürecinde işlem süreleri kısaltılmış, ve cerrahi setlerin son kullanma tarihlerine göre verimli şekilde kullanılması sağlanmıştır.

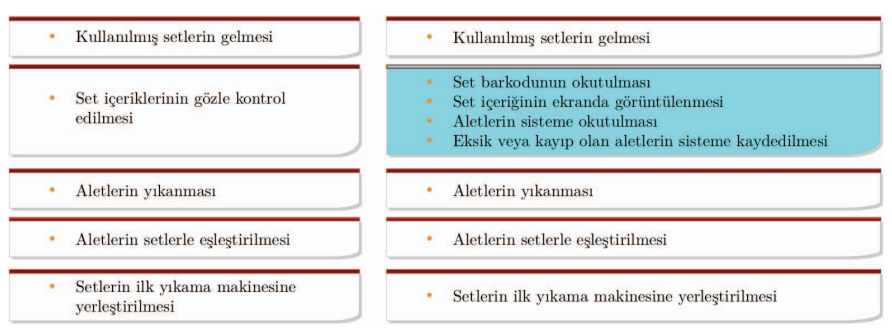

(a) Kirli Oda İşlemleri (Normal Prosedür (solda), CATS ile (sağda))

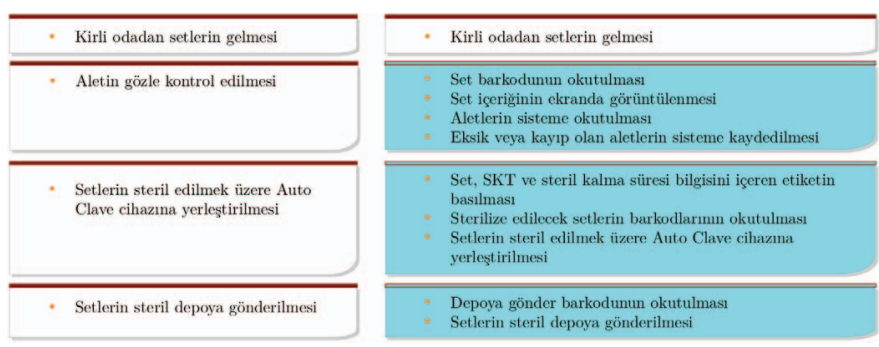

(b) Temiz Oda İşlemleri (Normal Prosedür (solda), CATS ile (sağda))

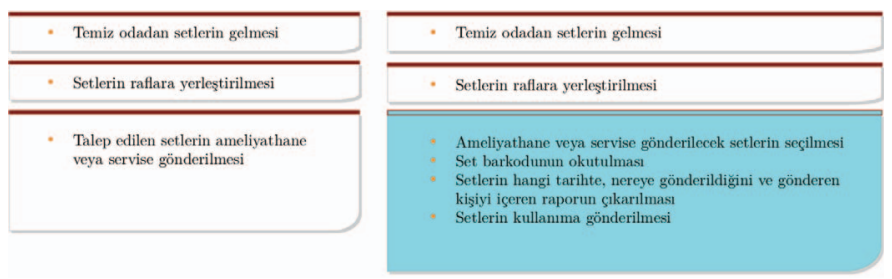

(c) Steril Depo İşlemleri (Normal Prosedür (solda), CATS ile (sağda))

Şekil 2: MSÜ'de Gerçekleştirilen Sterilizasyon İşlemleri (Normal Prosedür ve CATS Karşılaştırılması)

Projenin ileriye yönelik hedefleri arasında cerrahi setlere RFID etiketler yerleştirerek cerrahi konteynerleri dolayısıyla o konteynerlere bağlı cerrahi aletleri takip etmek yer almaktadır. $\mathrm{Bu}$ sayede, ilgili cerrahi aletin her döngüsü kayıt altına alınmasının yanı sıra o anda sağlık kurumunun hangi biriminde bulunduğu da takip edilebilecektir.

\section{KAYNAKÇA}

[1] J. I. Shipp, "Surgical instrument recycling and tracking system," Dec. 20 1994, uS Patent 5,374,813.

[2] D. Swenson, "Designing and developing a central sterile supply department," Biomedical Instrumentation \& Technology, vol. 47, no. 3, pp. 259-265, 2013.

[3] O. Koçak, B. Özgöde, A. Koçoğlu, and O. Eroğul, "A clinical engineering approach for design and management of central sterilization units," in TIPTEKNOi15. IEEE, 2015, pp. 1-5.

[4] M. S. Ü. M. MSÜ and F. AYDIN, "Msü'nün mimari yapısı ve donanımı."

[5] Y. Yavuz, "Esencan hastanesİnde sterỉl alet takİplerİnde bantlama ve kare barkod yÖntemİnİ karŞilaŞtirlmasi," in 2. Ulusal Sterilizasyon Ameliyathane Dezenfeksiyon Kongresi. DAS, 2014, p. 314.

[6] N. Ayar, R. Dag, D. Mehel, and M. Sen, "Hasta güvenliği açısından sterilizasyon sürecinde karekod uygulaması," in 5. Uluslararasi Saglikta Performans ve Kalite Kongresi. T.C. Saglik Bakanligi, 2014, pp. 665-665.

[7] Colak and U. Guzel, "Accreditation experience in central sterilization unit," in 14th World Sterilization Congress. WFHSS, 2014, pp. 196-197. 